\title{
Effect of fluorometholone (FML) on the intraocular pressure of corticosteroid responders
}

\author{
E. MORRISON AND D. B. ARCHER \\ From the Department of Ophthalmology, The Queen's University of Belfast, Eye and Ear Clinic, \\ Royal Victoria Hospital, Belfast, Northern Ireland
}

SUMmARY Steroid responsiveness to dexamethasone was determined in a large family with an established dominant form of chronic simple glaucoma. The high and intermediate steroid responders were then tested with fluorometholone-a steroid which is claimed to have a reduced risk of increasing intraocular pressure. It was found that fluorometholone had a much less pronounced ocular hypertensive effect than dexamethasone. However, one patient showed a comparable response on both drugs, and this suggests that some caution must still be exercised when using the drug on susceptible individuals. Fluorometholone was also found to be more irritable to the eye than dexamethasone.

In 1963 Becker and Mills' demonstrated that a proportion of normal individuals showed a rise in intraocular pressure after the topical administration of corticosteroids (steroid responders). This response was more common in close relatives of patients with open-angle glaucoma, and this hypertensive phenomenon has proved a useful technique in studying the inheritance of this condition. ${ }^{2.3}$ Armaly ${ }^{4}$ and Becker and $\mathrm{Hahn}^{5}$ hypothesised that the intraocular pressure response to topical corticosteroids is inherited in an autosomal recessive manner. They based their conclusions on the finding of three levels of response that corresponded to the homozygous positive (high responder), homozygous negative (low responder), and heterozygous (intermediate responder) states. Becker ${ }^{6}$ administered topical dexamethasone four times a day for six weeks and used the final intraocular pressure as a measurement of the response. Armaly, ${ }^{7}$ on the other hand, used dexamethasone drops three times a day for four weeks and identified responders according to the change in intraocular pressure.

The potential ocular hypertensive effect of local corticosteroids has limited their unrestricted and prolonged use. Complications are most likely in glaucoma patients and their first degree relatives, and in such instances prolonged use of corticosteroids may be hazardous if not contraindicated. A topical steroid with both anti-inflammatory and ocular hypotensive effects would be an attractive alternative to local Correspondence to Miss E. Morrison, FRCS. corticosteroid preparations. Fluorometholone (21deoxy-9-fluoro-6-methyl presnisolone) is an antiinflammatory steroid with some structural characteristics in common with progesterone (Fig. 1). Progesterone is a steroid which lacks substantial antiinflammatory activity but does reduce intraocular pressure. ${ }^{8}$ Fluorometholone has been found to possess progestational activity equivalent to progesterone and anti-inflammatory activity 25 to 30 times that of hydrocortisone. ${ }^{2-11}$

The anti-inflammatory and antihypertensive properties of fluorometholone have been investigated by a number of workers. Castroviejo ${ }^{12}$ studied the effect of fluorometholone on patients who had cataract surgery or keratoplasty and demonstrated good control of postoperative inflammation with little risk of increasing intraocular pressure. Mindel et al.$^{13}$ compared the relative effects of fluorometholone, medrysone, and dexamethasone on the intraocular pressures of normal patients. Fluorometholone was less hypertensive than dexamthasone but caused a greater increase in intraocular pressure than medrysone. Fairbairn and Thorson ${ }^{14}$ used fluorometholone on a group of patients with mild to severe non-infectious inflammatory disorders of the eye who had previously shown an increase in intraocular pressure when treated with other steroids. They found that increases in intraocular pressure following the administration of fluorometholone were not significant compared with those produced by other steroids. They also examined the effects of fluorometholone 
Fig. 1 Chemical structure of progesterone and fluorometholone.<smiles>CC(=O)C1CCC2C3CCC4=CC(=O)CCC4(C)C3CCC12C</smiles>

PROGESTERONe<smiles>CC(=O)C1(O)CCC2C3=CC(C)C4=CC(=O)C=CC4(C)C3(F)C(O)CC21C</smiles>

FLUOROMETHOLONE on a large random population, including many patients with glaucoma, and found no significant rise in intraocular pressure. Stewart and Kimbrough, ${ }^{15}$ on the other hand, showed that fluorometholone raised the intraocular pressure significantly in a number of corticosteroid responders. We were unable to find any reference in the literature to studies on close relatives of patients with glaucoma who had been shown to develop a high intraocular pressure after the administration of dexamethasone. We considered that if such a group of steroid sensitive individuals manifested no increase in intraocular pressure after the administration of fluorometholone it would be a significant finding.

\section{Patients and methods}

A large family with an established dominant form of chronic simple glaucoma was available to us for testing (Fig. 2). From a pedigree of 65 members six persons suffered from open-angle glaucoma. Eighteen unaffected members of the family were tested for steroid responsiveness using the method described by Becker et al. ${ }^{3}$ that is, dexamethasone $0.1 \%$ four times a day for six weeks. A low response was recorded as less than $20 \mathrm{mmHg}$, an intermediate response as 20 to 30 $\mathrm{mmHg}$, and a high response as greater than $31 \mathrm{mmHg}$. Of the 18 individuals tested 15 attended for follow up, and of these eight $(44.5 \%)$ were high responders, 6 $(33.3 \%)$ were intermediate, and one $(5.5 \%)$ was a low responder (Fig. 3). The high and intermediate responders were tested with fluorometholone to assess its effect on intraocular pressure. Seven (14 eyes) of the eight high responders were available for testing and three (6 eyes) of the intermediate responders. Informed consent was obtained from all patients. Each patient was examined by one person (E.M.) and a mean of three intraocular pressure measurements taken as the baseline pressure. Fluorometholone $(0 \cdot 1 \%)$ was prescribed four times a day for six weeks and the intraocular pressure reassessed as described above. Excellent drug compliance was obtained in all patients.

\section{Results}

Three of seven patients categorised as high corticosteroid responders had a rise in intraocular pressure in both eyes six weeks after the instillation of fluorometholone drops (Fig. 4). Two patients (four eyes) had a small increase in intraocular pressure in comparison with the response to dexamethasone, but one patient (two eyes) had a significant increase comparable with the response obtained with dexamethasone.

None of the patients graded as intermediate
Fig. 2 Pedigree of family with dominantly inherited open-angle glaucoma.

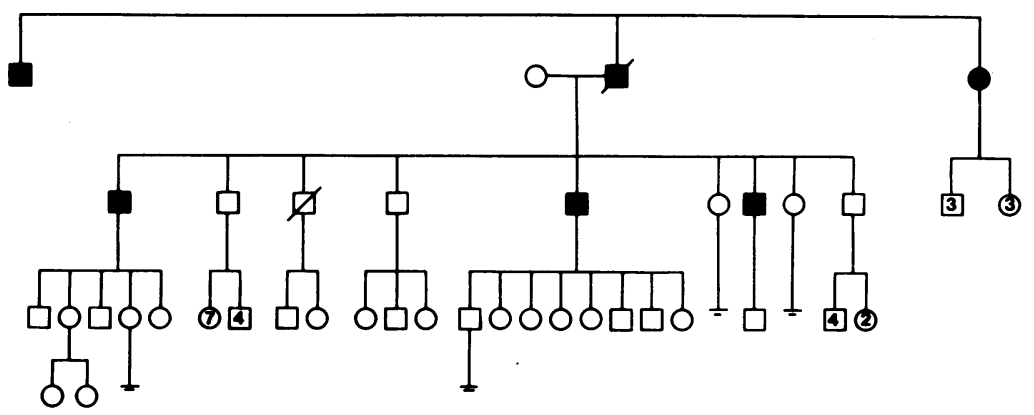




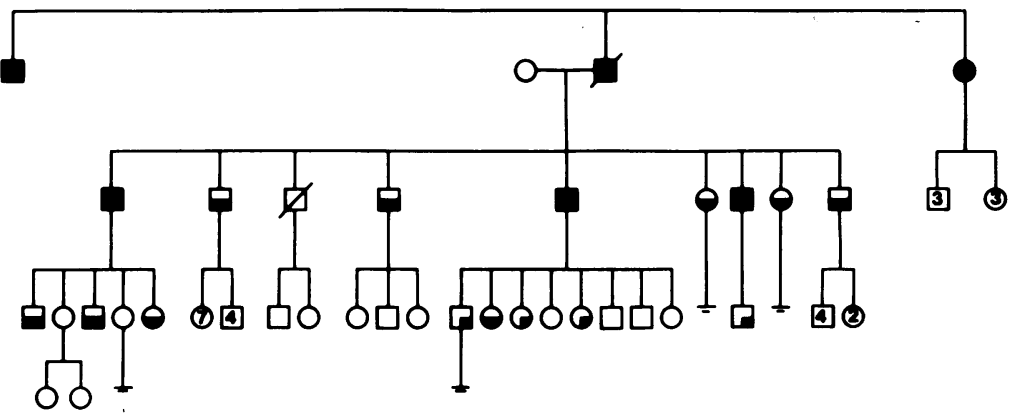

HICH RESPONDER

O NTERMEDIATE RESPONDER

responders had a significant rise in intraocular pressure with fluorometholone (Fig. 5). Two patients complained of an unpleasant taste in the mouth that persisted for 1 to 2 hours after instillation of the drops. All patients, with one exception, volunteered that the fluorometholone drops were more irritant to their eyes than dexamethasone drops.

\section{Discussion}

Known corticosteroid responders who are the first degree relatives of patients with glaucoma are probably the most sensitive group to test the ocular hypertensive properties of a steroid preparation. The pedigree of patients with dominant open-angle glaucoma described in this report was sufficiently large to allow the identification of several corticosteroid responders, most of whom were categorised as high responders. The result of testing these patients with dexamethasone correlated closely with the hypothesis of Becker and Armaly of an autosomal recessive-type inheritance of steroid responsiveness.
Tests with fluorometholone showed that the majority of the high steroid responders in the study did not demonstrate a significant rise in intraocular pressure. Two patients (four eyes) had a slight rise above normal, and one patient (two eyes) developed an intraocular pressure comparable with that induced by dexamethasone. None of the intermediate responders showed any abnormal rise in intraocular pressure with fluorometholone.

These results provide further evidence that fluorometholone has a much less pronounced ocular hypertensive effect than dexamethasone. The finding that seven of eight high corticosteroid responders were not affected by- fluorometholone is significant and suggests that fluorometholone is unlikely to induce a serious rise in intraocular pressure in the vast majority of patients. Nevertheless, one high responder did show a rise comparable with that produced by dexamethasone, which shows that some caution must still be exercised when using this drug particularly in susceptible individuals.

It was notable that most patients complained of



Fig. 4 High steroid responders comparing intraocular pressure rise to dexamethasone and fluorometholone. 


\section{INTERMEDIATE RESPONDERS}

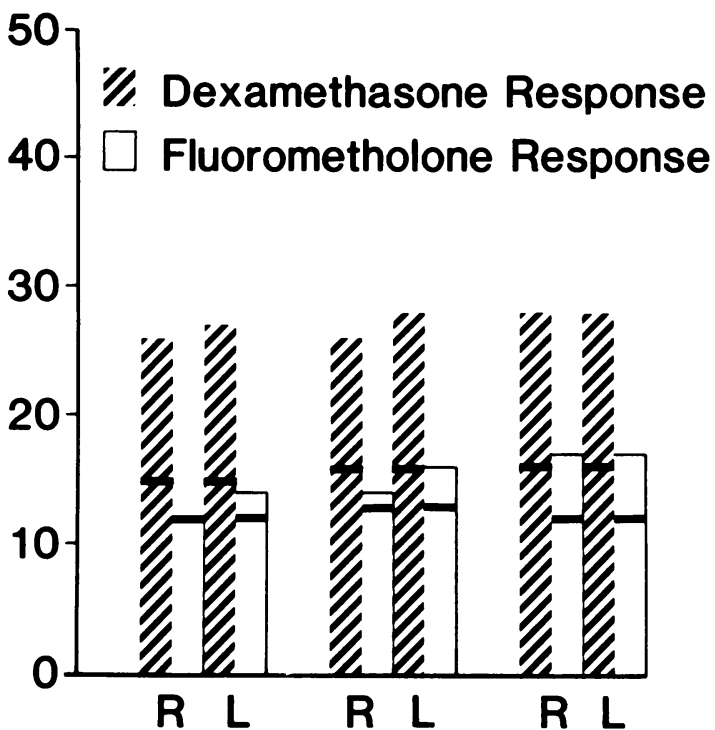

Fig. 5 Intermediate responders comparing pressure response to dexamethasone and fluorometholone.

local irritation after the instillation of fluorometholone drops into the eye, a finding that has not been emphasised previously. Furthermore, two patients complained of a persistent bad taste in the mouth following the use of fluorometholone, and it may be that this response was related to the patients' genetic constitution.

\section{References}

1 Becker B. Mills DW. Corticosteroids and intraocular pressure. Arch Ophthalmol 1963; 70: 50)-7.

2 Armaly MF. On the distribution of applanation pressure. I. Statistical features and the effect of age, sex and family history of glaucoma. Arch Ophthalmol 1965; 73: 11-8.

3 Becker B, Kolker AE, Roth RD. Glaucoma family study. Am J Ophthalmol 1960; 50: 557-67.

4 Armaly MF. Inheritance of dexamethasone hypertension and glaucoma. Arch Ophthalmol 1967; 77: 747-51.

5 Becker B, Hahn KA. Topical corticosteroids and heredity in primary open-angle glaucoma. Am J Ophthalmol 1964; 57: 54351.

6 Becker B. Intraocular pressure response to topical corticosteroids. Invest Ophthalmol Visual Sci 1965; 4: 198-205.

7 Armaly MF. Topical dexamethasone and intraocular pressure. In: Leydhecker W, ed. International symposium on glaucoma. Tutzing, 1966. Basel: Karger, 1967: 73-7.

8 Posthumus RG. The use and the possibilities of progesterone in the treatment of glaucoma. Ophthalmologica 1952; 124: 17-25.

9 Glenn EM. Miller W, Schlagel CA. Metabolic effects of adrenocortical steroids in vivo and in vitro. Relationship to antiinflammatory effects. Recent Prog Horm Res 1963; 19: 107-99.

10 Schlagel CA, Northam JI, Comparative anti-inflammatory efficacy of topically applied steroids on human skin. Proc Soc Exp Biol Med 1959; 101: 629-32.

11 Mass RE. Clinical evaluation of Oxylone (NSC-33001). Cancer Treat Rep 1964; 38: 49-60.

12 Castrovicjo R. Procecdings of the 79th Annual Mecting of the American Academy of Ophthalmology and Otolaryngology Dallas, Texas, 6-10 October 1974. Klin Monatsbl Augenheilkd 1975; 166: 518-20.

13 Mindel JS, Tavitian HO, Smith H, Walker EC. Comparative ocular pressure elevation by medrysone, fluorometholone and dexamethasone phosphase. Arch Ophthalmol 1980; 98: 1577-8.

14 Fairburn WD, Thorson JC. Fluorometholone anti-inflammatory and intraocular pressure effects. Arch Ophthalmol 1971; 86: $138-41$.

15 Stewart RH, Kimbrough RL. Intraocular pressure response to topically administered fluorometholone. Arch Ophthalmol 1971: 97: $2139-40$. 